\title{
Correction to: Antiplasmodial Effect of Nano Dendrimer G2 Loaded with Chloroquine in Mice Infected with Plasmodium berghei
}

\author{
Taher Elmi ${ }^{1} \cdot$ Mehdi Shafiee Ardestani ${ }^{2} \cdot$ Manijeh Motevalian $^{3} \cdot$ Ali Kalantari Hesari $^{4} \cdot$ Mohammad Seyyed hamzeh $^{2}$. \\ Zahra Zamani $^{5}$. Fatemeh Tabatabaie ${ }^{6}$ (I)
}

Published online: 25 November 2021

(c) The Author(s) under exclusive licence to Witold Stefański Institute of Parasitology, Polish Academy of Sciences 2021

\section{Correction to: Acta Parasitologica https://doi.org/10.1007/s11686-021-00459-4}

Unfortunately, an error occurred in the author affiliations. The first and fourth addresses were wrong. The correct affiliations are given below:

1 Department of Laboratory Science, Babol Branch, Islamic Azad University, Babol, Iran

4 Department of Pathobiology, Faculty of Veterinary Science, Bu-Ali Sina University, Hamedan, Iran

The original article has been corrected.
The original article can be found online at https://doi.org/10.1007/ s11686-021-00459-4.

\section{Zahra Zamani}

zamani@pasteur.ac.ir

$\triangle$ Fatemeh Tabatabaie

tabatabaei.f@iums.ac.ir; Tabatabaie59@gmail.com

Taher Elmi

elmi1364@yahoo.com

Mehdi Shafiee Ardestani shafieeardestani@gmail.com

Manijeh Motevalian motevalian.m@iums.ac.ir

Ali Kalantari Hesari kalantari.ali67@gmail.com

Mohammad Seyyed hamzeh m.s.hamzeh@gmail.com
Publisher's Note Springer Nature remains neutral with regard to jurisdictional claims in published maps and institutional affiliations.
1 Department of Laboratory Science, Babol Branch, Islamic Azad University, Babol, Iran

2 Department of Radiopharmacy, Faculty of Pharmacy, Tehran University of Medical Sciences, Tehran, Iran

3 Department of Pharmacology and Razi Drug Research Center, Iran University of Medical Sciences, Tehran, Iran

4 Department of Pathobiology, Faculty of Veterinary Science, Bu-Ali Sina University, Hamedan, Iran

5 Biochemistry Department, Pasteur Institute of Iran, Pasteur Avenue, Tehran, Iran

6 Department of Parasitology and Mycology, School of Medicine, Iran University of Medical Sciences, Tehran, Iran 